figured, one hundred and fifty in number, seem to have been well selected, and the plates in which they are represented by Mr. Keulemans are in the style which has won him so much reputation as an ornithological artist. But all these merits pale before the admiration which the bold conception and patient execution of this grand undertaking excites. There is no English work on natural history comparable in these respects with the "Biologia CentraliAmericana," and the only foreign one which it calls to remembrance is the marvellous "Madagascar" of the late M. Grandidier. The debt due by naturalists of all branches and of all countries to the enterprise, the zeal, and the perseverance of both Messrs. Salvin and Godman, and to the munificence of the latter, for without that all the rest would have availed little or nothing, is one that can never be repaid.

A. N.

\section{VECTOR MECHANICS.}

Die Grundlagen der Bewegungslehre von einem modernen Standpunkte aus. By Dr. G. Jaumann. Pp. vi +422. (Leipzig: J. A. Barth, 1905.)

T'HIS work is intended as a systematic general introduction to mechanics; as in the recent English exposition of Webster, the whole field of solid and deformable bodies is considered, so that the book has a wide range--a feature which must necessarily be purchased to some extent at the expense of depth.

Dr. Jaumann, following a method which now enjoys some popularity on the Continent, treats the subject by vectorial methods throughout. The first chapter introduces the ideas of velocity and acceleration, and with them the ideas of the vector and the scalar and vector products of two vectors. This is very natural and well written; it is, however, followed by the introduction of dyads, which was scarcely to be expected at this early stage of the work; and when the author, as is the habit of those writers who apply vectors, takes the liberty of making some additions to the vector calculus itself, and plunges us forthwith into an able but somewhat difficult discussion of " rotary" dyads, we are thrown into doubt as to the class of readers for whom the book is designed.

After this we come back to the ideas of partial and absolute acceleration, illustrated by astronomical considerations, and to the conception of gravitation, with an account of Kepler's laws. This closes the first section of the book, which, though interesting, leaves an unsatisfied and helpless feeling behind it, for the student (if the book is written for students) has not learnt how to find for himself the path of a point in a given field of acceleration, which is surely the main problem of this part of the subject. Thus, although Foucault's pendulum is described, the theory of itwhich would make no greater demand on the mathematical capacity of the reader than the rotary dyads require-is not worked out.

The author now introduces the idea of mass, which is defined (as in most good modern works) by means of what used to be called the principle of action and NO. 1855 , vOL. 72$]$ reaction; in other words, the ratio of the masses of two particles is defined as the ratio of the accelerations which they induce in each other when moving under each other's influence, and the idea of "force" is altogether abandoned. These ideas are again supplemented by astronomical illustrations, even the tides being worked into the scheme; and after this we have more vector calculus, with Stokes's theorem in the vector notation.

Dr. Jaumann next discusses rigid bodies, rigidity itself being defined by a vector equation! He discusses the constants of inertia, and solves some very elementary problems, and then passes on to a sketch of acoustics.

The last principal division of the book deals with deformable media-elastic solids, liquids, and gases. The treatment here is good so far as it goes, but too slight to be very satisfying.

Considering the work as a text-book, it must be said that the difficulty of the vectorial methods so freely used is hopelessly out of proportion to the results achieved. The student who has mastered the whole machinery of the treatise will still be unable to solve for himself any but the most rudimentary of the actual problems of dynamics. The author seems to overlook the cardinal fact that the solution of every moving material system depends ultimately on the integration of the associated differential equation, or some equivalent process, and that this is the really difficult part of the subject, the rest being child's play in comparison. A book which devotes scores of pages to symbols and formulæ, and yet never brings the reader into close grip with this essential kernel of the subject, is open to the charge of beating about the bush.

\section{GREATER AUSTRIA.}

Geologie der Umgebung von Sarajevo. By Ernst Kittl. Part iv. of the Jahrbuch der k.k. geologischen Reichsanstalt for 1903. (Vienna: R. Lechner, 1904.)

THIS general essay, with its plates of fossils and numerous geological sections in the text, corresponds to one of the memoirs on special districts issued by our own Geological Survey. It includes, moreover, a folded geological map on the scale of $1: 75,000$, and is thus a complete guide for future scientific visitors. The map itself reminds us of the charm of the Bosnian capital, set in its semicircle of craggy hills, where the gorge of the Miljačka broadens out towards the alluvial basin of Ilidže. We trace the mountain-road from the Ivan Pass coming out suddenly on this cultivated plain, and see again the minarets of Sarajevo shining like white masts under the background of Triassic precipices.

The author's introduction shows how the geological survey by Austrian observers followed hard upon the capture of the city, which had risen fanatically to arms. The famous ammonite-locality of Han Bulog, on the way to Mokro, was thus discovered as early as 1880 ; and the important part played by Triassic rocks east of Sarajevo was made known by 